\title{
Outdoor Water Use and Water Conservation Opportunities in Virginia Beach, Virginia
}

\section{Water Conservation is Important to Virginia Beach}

How much water do you use to water your lawn, wash your car, or fill your swimming pool? Your answers to these questions have important implications for water supplies in the City of Virginia Beach. To help find the answers, the City cooperated with the U.S. Geological Survey (USGS) and Old Dominion University to learn more about seasonal outdoor water use. In the summer of 2008 the USGS surveyed city residents and asked detailed questions about their outdoor water use. This fact sheet describes what was learned in the survey.

The amount of seasonal water use, such as the lawn watering shown in figure 1 , is important to the City of Virginia

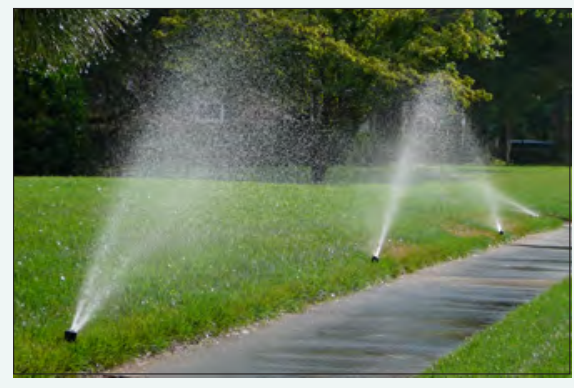

Figure 1. A typical residential irrigation system operating in the City of Virginia Beach, Virginia.

Beach because the primary source of this water is a fragile, shallow aquifer that is the only fresh groundwater source available within the City. Residents in the mostly rural southern half of Virginia Beach (fig. 2) rely solely on this aquifer, not only for outdoor water uses but also for indoor domestic uses such as drinking and bathing. Groundwater that is close to the land surface in Virginia Beach is mostly fresh, whereas water 200 feet or more below the land surface is mostly saline and generally too salty to drink or use for irrigating lawns and gardens (fig. 3).

\section{Groundwater is a Fragile and Valuable Resource}

More than 20,000 private wells in the northern portion of Virginia Beach (fig. 2) tap fresh groundwater in the shallow aquifer system (fig. 3). The pumping from these many wells often causes groundwater levels to drop below sea level, as referenced to the

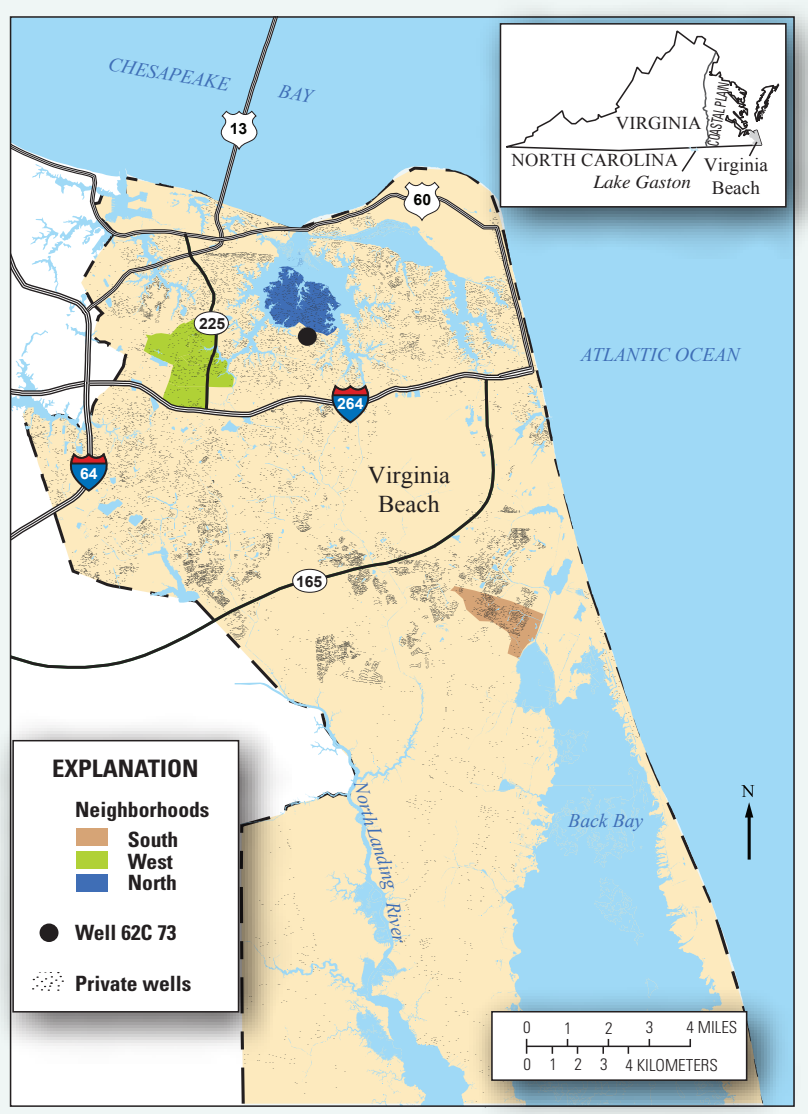

Figure 2. The City of Virginia Beach, Virginia, showing locations of private wells and neighborhoods surveyed in 2008.

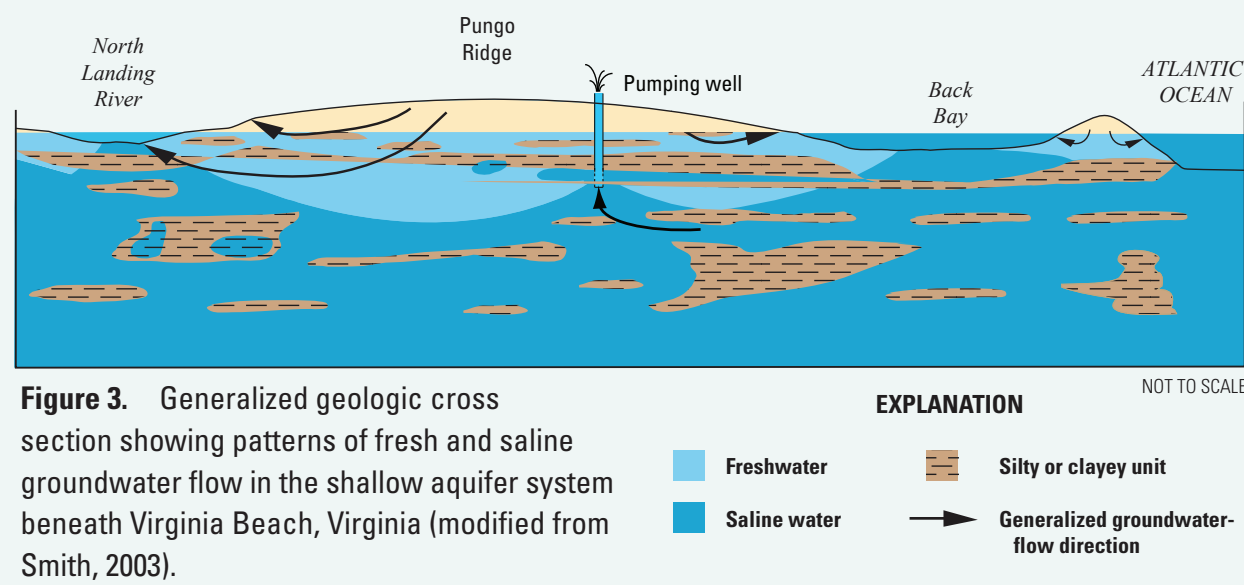

North American Vertical Datum of 1988 (NAVD 88), during the summer (fig. 4). When groundwater levels are below NAVD 88, salty sea water can intrude and mix with fresh groundwater, which increases chloride concentrations in the water, potentially making it unusable. Increasing chloride concentrations in groundwater measured by the USGS indicate that saltwater intrusion may be occurring in some parts of the City.

\section{Water-Use Survey Results}

To learn more about groundwater use from private wells, a survey was mailed in the summer of 2008 to 999 households in northern Virginia Beach. Three neighborhoods, located in the northern, western, and southern portions of northern Virginia Beach and shown in figure 2 , were chosen to represent diverse water-use populations within the City. Addresses in these neighborhoods were randomly selected to receive the survey. In order to determine water-use patterns for each of the three neighborhoods, residents were asked to complete the surveys anonymously and mail them back. A good response rate (287 out of 999 , or 29 percent of the surveys) was achieved, which indicates that Virginia Beach residents are 


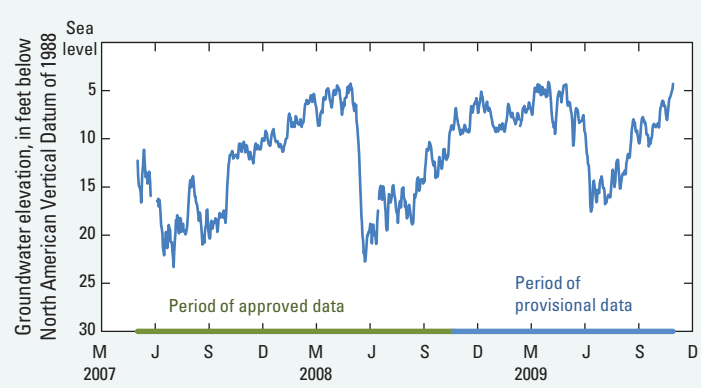

Figure 4. Groundwater levels in well 62C 73 are below North American Vertical Datum of 1988, probably as a result of nearby groundwater pumping.

concerned about and interested in their water supplies.

Characteristics of the three surveyed neighborhoods are shown in table 1 . Over 80 percent of the respondents reported using water from a private well, with the highest rate reported in the northern neighborhood (93 percent). Because all surveyed neighborhoods are supplied with public water by the City, only 5 percent of privatewell users reported using groundwater for domestic drinking water. Nearly every respondent with a private well (234 of 237) reported using groundwater for irrigating a lawn and(or) garden (table 2).

Irrigation water use was estimated from responses to questions about watering-system types, frequency and timing of irrigation, and numbers of hoses, sprinklers, and sprayers used. By combining these numbers with flow-rate estimates for different irrigation equipment, average household irrigation water use was estimated for each neighborhood. Irrigation is by far the largest category of private-well water use, accounting for 19,800 of the 28,700 gallons per year of water from the average household private well (table 3 ).

\section{Total Groundwater Pumped for Seasonal Outdoor Use in Northern Virginia Beach}

The total groundwater pumping rate from private wells for outdoor use in Virginia Beach was estimated based on survey results. Results for surveyed neighborhoods were extrapolated to other areas of the City based on mean property values and ages of the homes.

Pumping of water from private wells for outdoor use increases during warm months. For the months of June through August, the total pumping rate for the City is estimated to be 21.5 million gallons per day (Mgal/d). The annual average for pumping from private wells throughout the entire City is estimated to be $10.8 \mathrm{Mgal} / \mathrm{d}$.

Table 1. Virginia Beach neighborhood sampling results in 2008. Property ages and values were derived from cadastral data supplied by the City of Virginia Beach.

\begin{tabular}{lccccc}
$\begin{array}{c}\text { Neighbor- } \\
\text { hood }\end{array}$ & $\begin{array}{c}\text { Number of } \\
\text { residences }\end{array}$ & $\begin{array}{c}\text { Average property } \\
\text { value }\end{array}$ & $\begin{array}{c}\text { Mean residence } \\
\text { age }\end{array}$ & $\begin{array}{c}\text { Number of com- } \\
\text { pleted surveys }\end{array}$ & $\begin{array}{c}\text { Residences using } \\
\text { private wells }\end{array}$ \\
\hline North & 1,270 & $\$ 559,145$ & 1980 & 118 of $342(35 \%)$ & $110(93 \%)$ \\
West & 5,646 & $\$ 209,783$ & 1966 & 47 of $269(17 \%)$ & $30(64 \%)$ \\
South & 1,479 & $\$ 367,495$ & 1989 & 122 of $388(31 \%)$ & $97(80 \%)$ \\
\multicolumn{2}{l}{ Mean (entire sample) } & $\$ 290,420$ & 1972 & 287 of $999(29 \%)$ & $237(83 \%)$ \\
\hline
\end{tabular}

Table 2. Water-use categories identified by surveyed Virginia Beach residents with private wells in 2008.

\begin{tabular}{lccrr} 
Neighborhood & $\begin{array}{c}\text { Domestic (drinking, } \\
\text { bathing, etc.) }\end{array}$ & Washing cars & Filling pools & Watering lawns \\
\hline North & $6(5 \%)$ & $42(38 \%)$ & $17(15 \%)$ & $109(99 \%)$ \\
West & $0(0 \%)$ & $20(67 \%)$ & $5(17 \%)$ & $29(97 \%)$ \\
South & $7(7 \%)$ & $34(35 \%)$ & $10(10 \%)$ & $96(99 \%)$ \\
All & 13 of $237(5 \%)$ & 96 of $237(41 \%)$ & 32 of $237(14 \%)$ & 234 of $237(99 \%)$ \\
\hline
\end{tabular}

Table 3. Use of private well water by category, in gallons per household per year.

\begin{tabular}{lrrccc}
$\begin{array}{l}\text { Neighbor- } \\
\text { hood }\end{array}$ & Indoor & Car washing & Pool filling & Lawn irrigation & Total \\
\hline North & 5,600 & 500 & 4,300 & 39,800 & 50,300 \\
West & 0 & 600 & 6,400 & 3,000 & 10,000 \\
South & 6,200 & 500 & 2,400 & 16,700 & 25,800 \\
Mean & 3,900 & 500 & 4,400 & 19,800 & 28,700 \\
\hline
\end{tabular}

\section{What Can You Do to Conserve Water and Protect the Virginia Beach Shallow Aquifer?}

By reducing the amount of water pumped from wells, Virginia Beach residents can help protect groundwater from saltwater intrusion.

- Turn off irrigation systems and sprinklers when rain has occurred or is in the forecast.

- Avoid over-irrigating. Most lawns only need about one inch of water per week during the growing season.

- Check your irrigation system control settings. Water early in the morning to reduce evaporation rates.

- Use weather monitoring or soil-moisture monitoring devices to automatically cease irrigation on rainy days.

- Landscape with drought-tolerant native plants. Grass requires more water than native plants or mulched gardens.

- Find and fix leaking outdoor faucets and hoses.

- Install rainwater-collection systems or rain barrels with screened lids to collect and use roof runoff.

- Wash cars on grass or gravel so water can soak back into the ground.

\section{Cited References}

Smith, B.S., 2003, Ground-water flow and saline water in the shallow aquifer system of the southern watersheds of Virginia Beach, Virginia: U.S. Geological Survey Water Resources Investigations Report 03-4258, 67 p.

John R. Eggleston, Hydrologist jegglest@usgs.gov

\section{For additional information:}

Director, USGS Virginia Water Science Center 1730 East Parham Road

Richmond, Virginia 23228

(800) 684-1592

http://va.water.usgs.gov

or

Katie Rider, Virginia Beach Public Utilities (757) 385-4948

http://www.VBgov.com/dpu 